\title{
Jean-Jacques Viton, Il commento definitivo. Poesie
}

\section{4-2008}

\section{Fabio Scotto}

\section{Q OpenEdition \\ 1 Journals}

\section{Edizione digitale}

URL: http://journals.openedition.org/studifrancesi/5772

DOI: 10.4000/studifrancesi. 5772

ISSN: 2421-5856

\section{Editore}

Rosenberg \& Sellier

\section{Edizione cartacea}

Data di pubblicazione: 1 septembre 2011

Paginazione: 459

ISSN: 0039-2944

\section{Notizia bibliografica digitale}

Fabio Scotto, «Jean-Jacques Viton, I/ commento definitivo. Poesie 1984-2008», Studi Francesi [Online], 164 (LV | II) | 2011, online dal 30 novembre 2015, consultato il 08 janvier 2021. URL: http:// journals.openedition.org/studifrancesi/5772 ; DOI: https://doi.org/10.4000/studifrancesi.5772

Questo documento è stato generato automaticamente il 8 janvier 2021.

\section{(c) (i) $\odot$}

Studi Francesi è distribuita con Licenza Creative Commons Attribuzione - Non commerciale - Non opere derivate 4.0 Internazionale. 


\title{
Jean-Jacques Viton, Il commento definitivo. Poesie 1984-2008
}

\author{
Fabio Scotto
}

\section{NOTIZIA}

JEAN-JACQUES VITON, Il commento definitivo. Poesie 1984-2008, a cura di Andrea INGLESE, Postfazione di Nanni BALESTRINI, Pesaro, Metauro Edizioni, 2009 («Biblioteca di poesia, 5»), $276 \mathrm{pp}$.

1 Il poeta e traduttore francese Jean-Jacques Viton, nato a Marsiglia nel 1933, fondatore e cofondatore di significative riviste militanti come «Manteia» (1967-1974), «Banana Split» (1980-1990) e «La Nouvelle B.S.» (1990-2000) e oggi animatore di «If», è autore di una quindicina di libri. Nel suo ampio saggio introduttivo L'esplorazione dei resti (pp. 7-26), Andrea INGLESE, che è anche l'attento traduttore dei testi di questa antologia, fornisce argomenti di natura biografica e critica a supporto della sua scelta. Nei Motivi per un'antologia, che sono occasione per lamentare un'inadeguata conoscenza oggi in Italia della più recente poesia francese - ci sia consentito nel frattempo segnalare l'avvenuta pubblicazione dell'antologia a nostra cura Nuovi poeti francesi (Torino, Einaudi, 2011), che forse, almeno in parte, ha iniziato ad ovviare a questa lacuna, seppure con intenti storici rispettosi delle varie tendenze presenti sul campo, a nostro avviso quando valide tutte egualmente dignitose -, il curatore manifesta il duplice intento «documentario e militante» del suo lavoro volgendosi con Viton verso un «tutt'altro paesaggio» rispetto alle linee «Mallarmé-Bonnefoy» e «Rimbaudsurrealisti», a suo avviso ad oggi prevalenti nella ricezione italiana della poesia francese. Che tutt'altro paesaggio sia non vi è dubbio, pur se mai casuali e semmai alquanto complesse e storiche sono le ragioni della ricezione di una data poesia straniera in un Paese, e opinabili a ben vedere appaiono talune generalizzazioni, se è vero, come crediamo, che nessuna avanguardia sarebbe mai apparsa senza le innovazioni di Rimbaud e Mallarmé (basti pensare alla liberazione della spazialità della pagina attraverso l'iteratività, il passaggio alla prosa in poesia, ancor oggi elementi 
imprescindibili per tutte le ricerche avanguardistiche, siano esse installazioni, espressioni ibride e spurie o altro), come opinabile è il fatto che esista un asse «Mallarmé-Bonnefoy», se solo si guardi alla criticità dei numerosi saggi da Bonnefoy dedicati a Mallarmé e al suo sostanziale rifiuto del mondo per astrazione, opposto alla sua accettazione e al suo "consenso" allo stesso (Dans le leurre du seuil). Successivamente, dopo aver messo in risalto con partecipe entusiasmo i meriti storici di Viton, Inglese dice la difficoltà di scelta antologica posta da opere che si vogliono più «libri» che «raccolte», essendo difficile isolare frammenti da una poetica seriale dalle connotazioni molto particolari, per poi mettere in evidenza i tratti dominanti della poetica dell'autore che, superate iniziali ascendenze chariane, si volge verso un «movimento metonimico» il quale sovrappone «codice» e «corpo» in un «moto oscillatorio» di cui illustra le affinità e le differenze con la poetica di Ponge e degli italiani Pagliarani e Majorino. Lavoro di figurazione prossimo alla nozione forgiata da Virilio e Perec di infraordinario, l'interessante e originale opera di Viton è nell'argomentata e sentita lettura d'Inglese legata all'«assemblaggio», caro al modernismo statunitense (Pound, Williams), ma non nella modalità del montaggio (cutup), più propensa come essa pare alla valorizzazione di resti che sono «depositi densissimi di senso». 